\title{
Immediate Effects of Some Corrective Maintenance Interventions on Flexible Pavements
}

\begin{abstract}
Different maintenance interventions have different ability to address distresses on flexible pavements. Understanding the maintenance effects can benefit pavement maintenance decision-making. In this study, the immediate maintenance effects on roughness and rutting of three interventions including overlay, overlay with an additional base layer and mill \& fill were studied and compared. A method was introduced to validate maintenance effect models, using the pavement management information from Virginia Department of Transportation (VDOT). The method included a data mining process to extract data and apply regression analysis of maintenance effect models. The outliers in the analysis were detected and removed using the method of Cook's Distance. It was found that the immediate maintenance effects of overlay with base layer was greatest and mill \& fill was least when treating pavements with moderate roughness $(50-100 \mathrm{in} / \mathrm{mi}(\approx 0.8-1.6 \mathrm{~m} / \mathrm{km}))$. However, mill and fill was more useful for treating pavements with high roughness $(>100 \mathrm{in} / \mathrm{mi}(\approx 1.6 \mathrm{~m} / \mathrm{km}))$. Furthermore, suggestions were proposed on data collection for road authorities to improve the prediction of maintenance effects.
\end{abstract}

Key words: maintenance effect; pavement management system; data mining; model calibration; regression analysis

\section{Introduction}

Pavement maintenance can be classified on the basis of either application frequency, treatment intensity, cost or other factors (ISOHDM, 1995). Whichever classification 
system is used, it is to be expected that major interventions will be less frequent and more costly, while rapid surface repairs are less costly and are likely to be applied more frequently. In general, pavement maintenance includes routine, preventive, and corrective interventions (ISOHDM, 1995, Johanns and Craig, 2002). Routine maintenance is usually performed annually and includes interventions such as crack sealing \& filling, patching, and pothole filling. Routine maintenance such as crack sealing \& filling can only have minor effects on pavement performance, therefore routine maintenance was not considered in this study (ISOHDM, 1995).

Preventive maintenance is usually performed to improve the functional surface properties without significantly changing the structural properties of the pavement. The best time to apply the interventions is considered to be before significant distress is exhibited (Hicks et al., 2000). Typical preventive maintenance includes fog seal, chip seal, slurry seal, microsurfacing and thin overlay.

Corrective maintenance includes overlays, mill \& fill (rehabilitation), and reconstruction. Corrective maintenance can change the structural properties of the pavement and costs more but the effects (both immediate and long-term, see bullet points later) are usually greater. Structural distresses such as rutting can only be addressed by corrective maintenance. Corrective maintenance is usually triggered when maintenance thresholds are reached (MTAG, 2008), although earlier performed corrective maintenance may help to reduce road user costs (Qiao, 2015). Furthermore, the maintenance thresholds from different road agencies may be different, depending on maintenance budget and serviceability tolerance. 
The maintenance effects of various interventions usually include two parts:

- An immediate effect: an immediate improvement of conditions due to the intervention, which is the subject of this Technical Note; and

- A Long-term effect: an improvement in the rate of subsequent deterioration

The immediate improvement refers to the instant improvement in pavement conditions after a treatment, by comparing the conditions immediate before and after the treatment. By this definition, the immediate improvement is determined by the effectiveness of a specific treatment and is not related to traffic. The long-term effect is usually described in terms of the extended service life due to the intervention. For instance, overlays can extend the serviceability of a pavement for approximately $4-6$ years (Hicks et al., 2000, MTAG, 2008). Firstly, they may form a new surface of the pavement and prevent water intrusion from the surface into the pavement. Secondly, overlays may change the load spreading and thus change the critical stresses in the pavement. Thirdly, the material added may be more durable. Whatever the reasons, extension of service life is the result of complex interactions between the new and existing pavement layers, the local traffic and climate conditions (Qiao et al., 2013). Therefore, the same intervention applied on a different pavement may yield very different extensions to service life. But this long-term improvement is not studied further in this Technical Note.

Furthermore, the life-cycle costs of pavements can be significantly influenced by the maintenance activities that they received over their life time (Qiao et al., 2015). 
Thus, modelling of pavement maintenance will be helpful to understand the maintenance effectiveness of various interventions and this will assist pavement maintenance decision making and optimisation. Well-understood and validated maintenance effect models will help to reduce the life-cycle costs of highways.

\section{Problem statement}

When the maintenance of a pavement is being considered, the decision about whether or not to intervene, and about the type of intervention required, depends to a large extent on various factors such as feasibility of a strategy, availability of funding, and effects of maintenance i.e. the anticipated improvement that will be achieved. In practice, the degree of improvement required realized by maintenance activity is usually judged by reference to past experience. The use of predictions of the immediate effects of pavement maintenance interventions to guide maintenance decision-making has received some research study (ISOHDM, 1995, Odoki and Kerali, 1999). In practice, much of the information on past experience will be hidden in pavement management systems, but little literature was found to describe data extraction for calibration of maintenance effect models. This study introduces a method to validate immediate maintenance effects of three interventions on IRI and rutting, using pavement management data from the Virginia Department of Transportation (VDOT).

It is recognized that many highway agencies preferentially employ mill-and-overlay as their principal pavement maintenance technique. From a life-cycle costs point of view, this may not be the most economic approach in all circumstances as 
shown by Qiao (2015). So in this paper, three alternative options have been investigated, including a thin overlay, a thick overlay and mill \& fill.

Performance of flexible pavements can be indicated by measurements of distresses such as cracking, rutting, and IRI (International Roughness Index). Many road agencies perform annual distress surveys to monitor condition of highways. When the condition is poor, major maintenance and rehabilitation needs to be performed to improve road conditions. The major maintenance interventions can include many types and have different effects. These effects can be characterized by an improvement in performance indices (e.g. cracking, rutting, and IRI), which should be measured immediately before and after an intervention, if the effectiveness of the intervention is to be reliably assessed.

However, such immediate measurements may not always be available. Measurements are commonly performed annually i.e. the gap between readings is approximately one year. Therefore, the change in index value will include effects from maintenance (if there is any) and from deterioration that occurred between the two measurements. If the gap between readings is small (i.e. readings observed one day before and after an intervention), then the proportion of the effects from deteriorations should be negligible, especially for the interventions that are discussed in this study. Therefore, as a first approximation, the reductions in performance indices will be considered only from maintenance effects.

In this study, rutting and IRI measurements in the year of maintenance and in the year after the maintenance were used to determine the effect(s) of maintenance 
effects. Usually, it is difficult to determine whether the measurements or the maintenance were done early in the year of intervention, since the performance was only recorded by year. Therefore, the effect of maintenance may not be accounted for simply by the subtraction between performance indices measured in a certain year and the year after, as post-maintenance deterioration may have occurred before the next year's condition assessment. Furthermore, errors in the measurements may exist and thus the subtraction cannot represent maintenance effects accurately. To solve these problems, a data mining process was introduced to enhance maintenance effect modelling.

\section{Pavement Management Data}

A pavement management system (PMS) is a set of tools in part designed to assist the cost-effective decision making when evaluating and maintaining pavements. In this study, the Virginia PMS provided information including construction history and distress rating. This information was recorded in sections, typically with length of approximately 1 mile $(1.6 \mathrm{~km})$. The data that were used for model validation in this

study were extracted from the three most frequently maintained districts in Virginia, i.e. Bristol, Salem, and Richmond. As sections with construction history and with distress rating information did not always match, a data matching algorithm was created to combine the two sets of data together. The algorithm combined the latest maintenance activity records with the pavement condition indices measured in and after the year of maintenance by matching relevant pavement sections. Matching criteria included route 
hierarchy (interstate, primary, or secondary), directions, and begin \& end mile posts.

The pavement construction history provided information about the surface layer, which showed the latest intervention. The distress rating included pavement conditions measured between 2007 and 2012. The pavement condition indices measured in and after the year of the latest interventions were taken to be the pavement conditions before and after the maintenance. In some cases, this simplified approach led to some incorrect interpretation of distress state. This necessitated data correction, as discussed later.

\section{Immediate Improvement of Performance Indices}

Roughness (in IRI) and rutting, as the most important distresses on flexible pavements, were selected for the analysis. Cracking, another important distress, was not included in this study because both preventive and corrective maintenance tend to reset the pavement surface and thus reset visible cracking.

The changes in pavement condition, as defined by IRI and rutting, were calculated by subtracting the indices in and after the year of maintenance as follows:

$$
\begin{aligned}
& \Delta \mathrm{IRI}_{\mathrm{n}}=\mathrm{IRI}_{\mathrm{n} 0}-\mathrm{IRI}_{\mathrm{n} 1} \\
& \Delta \mathrm{Rut}_{\mathrm{n}}=\mathrm{Rut}_{\mathrm{n} 0}-\mathrm{Rut}_{\mathrm{n} 1}
\end{aligned}
$$

where,

$\Delta \mathrm{IRI}_{\mathrm{n}}=$ change in roughness $(\mathrm{in} / \mathrm{mi})$

$\mathrm{IRI}_{\mathrm{n} 0}=$ roughness measured in the year of an intervention $(\mathrm{in} / \mathrm{mi})$ 
$\mathrm{IRI}_{\mathrm{n} 1}=$ roughness measured in the year after the intervention (in/mi)

$\Delta$ Rut $_{\mathrm{n}}=$ change in rutting depth (in)

Rut $_{\mathrm{n} 0}=$ rutting measured in the year of an intervention (in)

Rut $_{\mathrm{n} 1}=$ rutting measured in the year after the intervention (in)

$\mathrm{n}=$ the number of the data point $(0,1, \ldots)$

The above equations aimed to calculate the improvement in pavement condition due to maintenance. However, several uncertainties were involved that might have biased the results, and measures were taken to reduce the uncertainties.

Firstly, the time for construction history and distresses was only measured in each year without a specific date and thus the performance measurement in the year of maintenance did not always mean the intervention was made after that measurement. However, if the distress rating was measured after the intervention, the change cannot reflect the improvement in the condition. In this case, the change $\left(\Delta \mathrm{IRI}_{\mathrm{n}}\right.$ and $\left.\Delta \mathrm{Rut}_{\mathrm{n}}\right)$ would be likely to be negative $\left(\mathrm{IRI}_{\mathrm{n} 0}-\mathrm{IRI}_{\mathrm{n} 1}<0\right.$; Rut $\left._{\mathrm{n} 0}-\mathrm{Rut}_{\mathrm{n} 1}<0\right)$ in theory, indicating the usual deteriorations occurred in the year. Therefore, data points with a negative change were screened out.

Secondly, the condition rating in/after the year of maintenance did not mean the immediate condition before/after maintenance. Therefore, Equation 1 and 2 may include the impact of some additional deterioration that occurred between the two measurements. The additional deterioration should be negligible for older flexible pavements, for which roughness and rutting development will largely have stabilised. In fact, the corrective maintenance interventions discussed in this paper were usually 
applied on older and more deteriorated pavements. When the corrective maintenance is performed, the improvement in performance indices can be so significant that the additional deterioration is comparatively negligible. Therefore, this second type of uncertainty was not considered to be significant. It is recognised that deterioration, including roughness and rutting, may be expected in the new overlay (new layer). However, it is considered that such deterioration will not be significant because the thickness of the overlay is relatively thin (up to 4 in $(\sim 100 \mathrm{~mm})$ ) while experience suggests that the percentage of rutting will be small (e.g. 1-3\%) (Qiao et al., 2014, Qiao et al., 2015).

Thirdly, abnormal values exist in the database. For instance, an unusual IRI of $1750 \mathrm{in} / \mathrm{mile}(\approx 27.6 \mathrm{~m} / \mathrm{km})$ was found (typical IRI: $100-700 \mathrm{in} / \mathrm{mi}(\approx 1.58-11.0$ m/km) (Sayers and Karamihas, 1998)). This may due to an expected condition e.g. bumps in the road. Whatever the reason is, such unusual measurements may bias the maintenance effects modelling as outliers and thus needs to be get rid of. Regression diagnosis was made using the Cook's Distance method (discussed below) to avoid bias due to outliers.

\section{Cook's Distance and Data Selection}

Cook's Distance (D) is used as a measurement of the influence of a data point for regression analysis. Cook's D for point i can be expressed as follow:

$$
D_{i}=\frac{\sum_{j=1}^{n}\left(\widehat{y_{j}}-\widehat{y}_{j}(i)\right)^{2}}{p M S E}, i=1,2, \ldots, n
$$

where, 
$\widehat{y_{j}}=$ the estimated mean of $\mathrm{y}$ at observation $\mathrm{j}$

$\widehat{y_{j}}(i)=$ the estimated mean of $y$ at observation $\mathrm{j}$ when the dataset excludes

observation i

$\mathrm{p}=$ the number of coefficients in the regression model

MSE = mean squared error based on all observations

When performing a linear regression, the regression line will change when a point is removed from the dataset. Points that result in the largest change in the regression line are said to have the greatest influence on the regression. Cook's D is calculated based on this principle.

The value of Cook's $\mathrm{D}$ of data points $\left(\Delta \mathrm{IRI}_{\mathrm{i}}\right.$ versus $\mathrm{IRI}_{\mathrm{i} 0}$ and $\Delta \mathrm{Rut}_{\mathrm{i}}$ versus $\mathrm{Rut}_{\mathrm{i} 0}$ ) from the three districts was calculated. As a rule of thumb, it was considered that the point was influential if $\mathrm{D}_{\mathrm{i}}>0.7$ (McDonald, 2002). Therefore, such points were excluded in the regression. Figure 1 is an example of Cook's D result for Option 1. The point with Cook's $\mathrm{D}=27.18$ and was neglected together with its rutting value. 


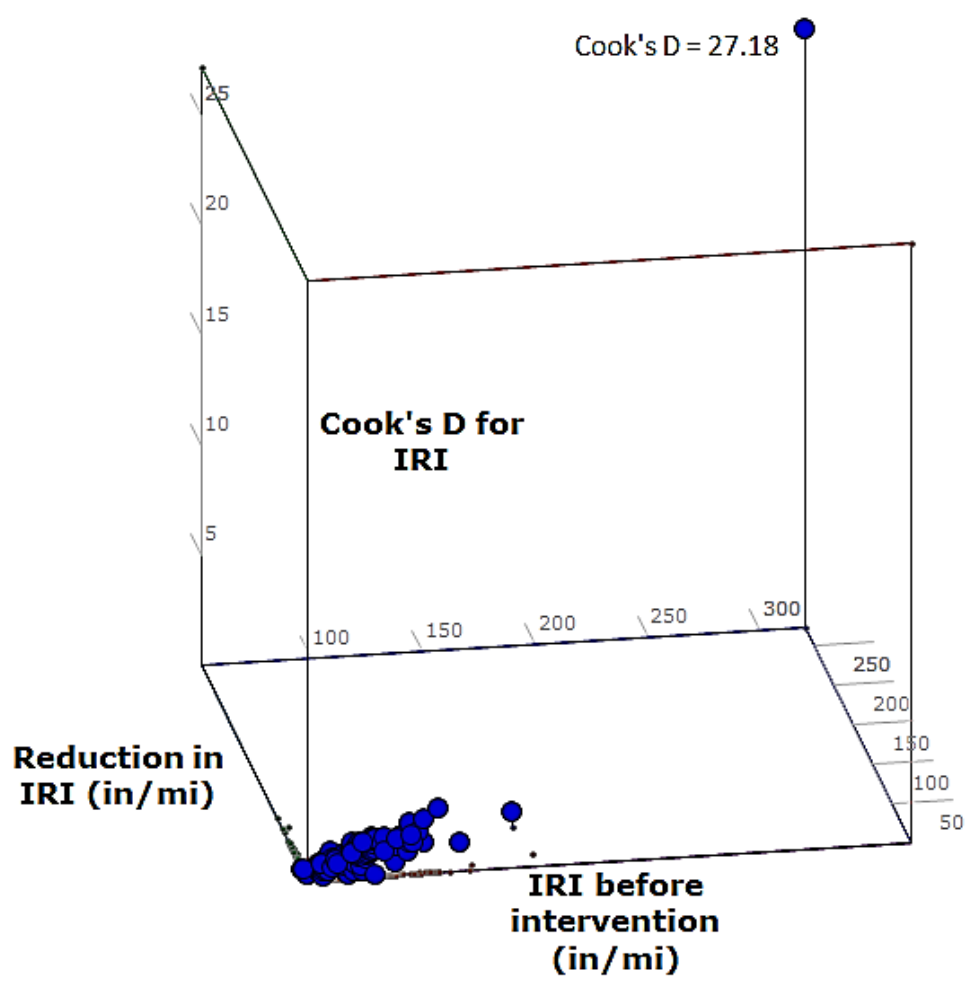

Figure 1. Cook's D results for Option 1.

As described above, the data selection process can be described using the flow chart shown as Figure 2: 


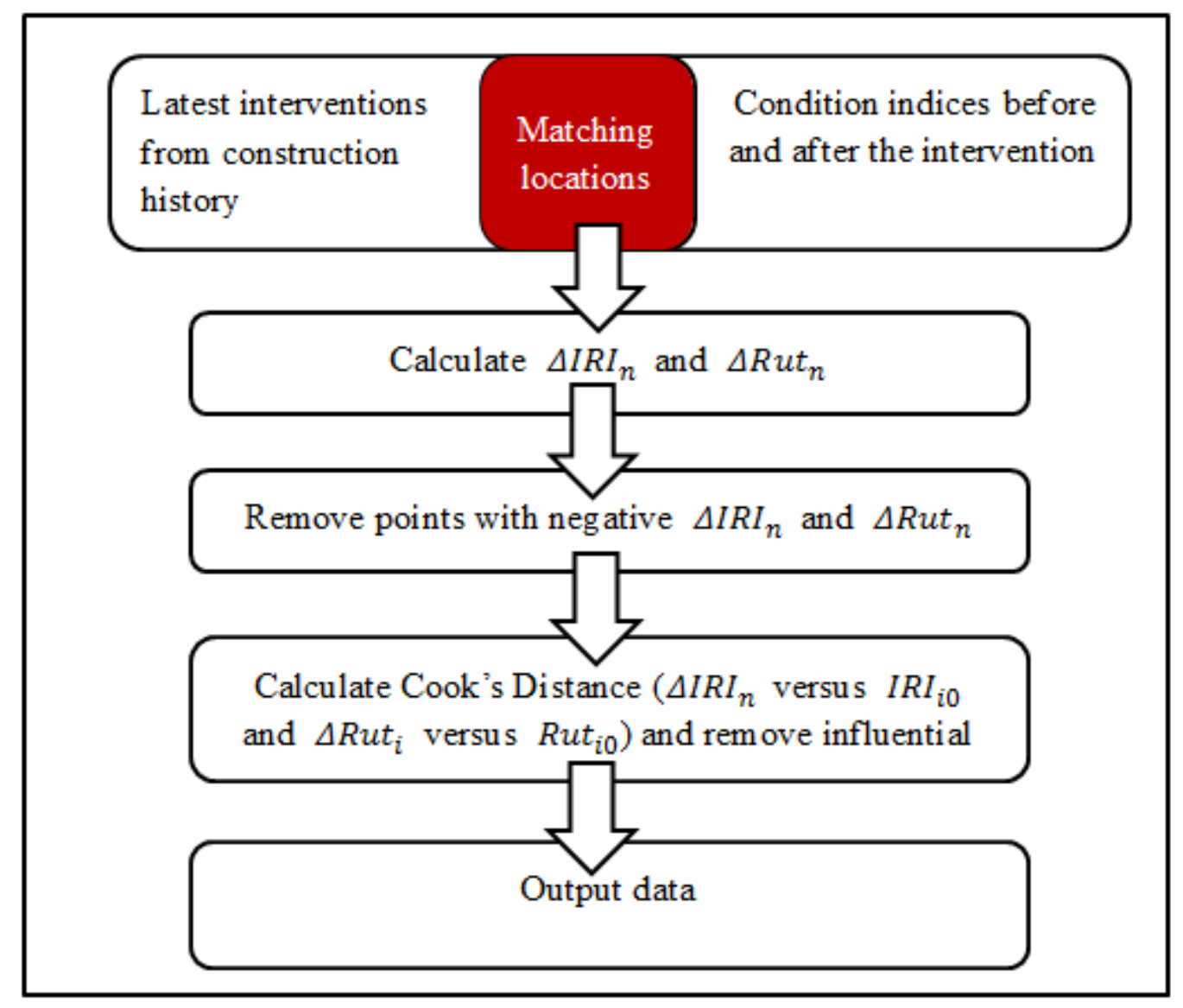

Figure 2. The process of data selection.

The selection started with matching the two sets of data including construction history and distress rating for inclusive sections. Then the changes in roughness $\left(\Delta \mathrm{IRI}_{\mathrm{n}}\right)$ and rutting $\left(\Delta \mathrm{Rut}_{\mathrm{n}}\right)$ can be calculated using Equation 1 and 2 . The points with negative $\Delta \mathrm{IRI}_{\mathrm{n}}$ and $\Delta \mathrm{Rut}_{\mathrm{n}}$ were removed to avoid the changes that cannot represent the real improvement. The remaining points were considered to be the performance before and after the maintenance. Cook's D value was then calculated for $\Delta I_{R} I_{i}$ versus $I_{R I} I_{i 0}$ and $\Delta$ Rut $_{\mathrm{i}}$ versus Rut $\mathrm{i}_{0}$ and any sections with $\mathrm{D}_{\mathrm{i}}>0.7$ were removed (McDonald, 2002). 


\section{Results and Discussions}

After data selection (Figure 2), there were 281 data points or sections on Interstate Route 81 and 77 that satisfied the selection criteria. There were three different maintenance interventions that had sufficient data for meaningful analysis including (1 in $=25.4 \mathrm{~mm})$ :

- Option 1: Overlay (SM-12.5D: thickness 1.5 in or 2 in or SM-12.5E: thickness 2 in)

- Option 2: Overlay (SM-12.5D: thickness 1.5 in or SM-12.5E: thickness 1.5 in) and a base mixture (BM-25.0: thickness 3 in) layer

- Option 3: Mill \& fill (Mill: thickness 2 in and SM-12.5E: thickness 2 in)

Option 2 and 3 are corrective maintenance. Option 1 can be either preventive or corrective because the "critical" thickness (according to experience) to distinguish between a preventive and corrective overlay is $1.5 \mathrm{in}$ (38 mm) (MTAG, 2008). SM and BM stand for surface mixture and base mixture respectively. The number 12.5 and 25.0 stands for the nominal maximum grain size $(\mathrm{mm})$ of the aggregates, which is defined as the sieve size greater than the sieve to retain more than $10 \%$ aggregates. SM-12.5 D and SM-12.5 E are with a Performance Binder (PG) grade of 70-16 and 76-22 respectively and are designed with somewhat different aggregate grading in order to meet specific criteria for rutting.

Figure 3 showed the IRI and rutting depth before and after the three options. In general, it can be observed that both IRI and rutting depth significantly decreased after 
the maintenance. The IRI-Rutting plots showed greater spread before the interventions while the maintenance interventions made concentrated the points together. On average, all three options can reduce roughness approximately by $35 \%$ (33\%, $41 \%$ and $32 \%$ for Option 1, 2 and 3 respectively). For rutting, the reduction is greater than $30 \%$ on average $(41 \%, 53 \%$ and $34 \%$ for Option 1,2 and 3 respectively).

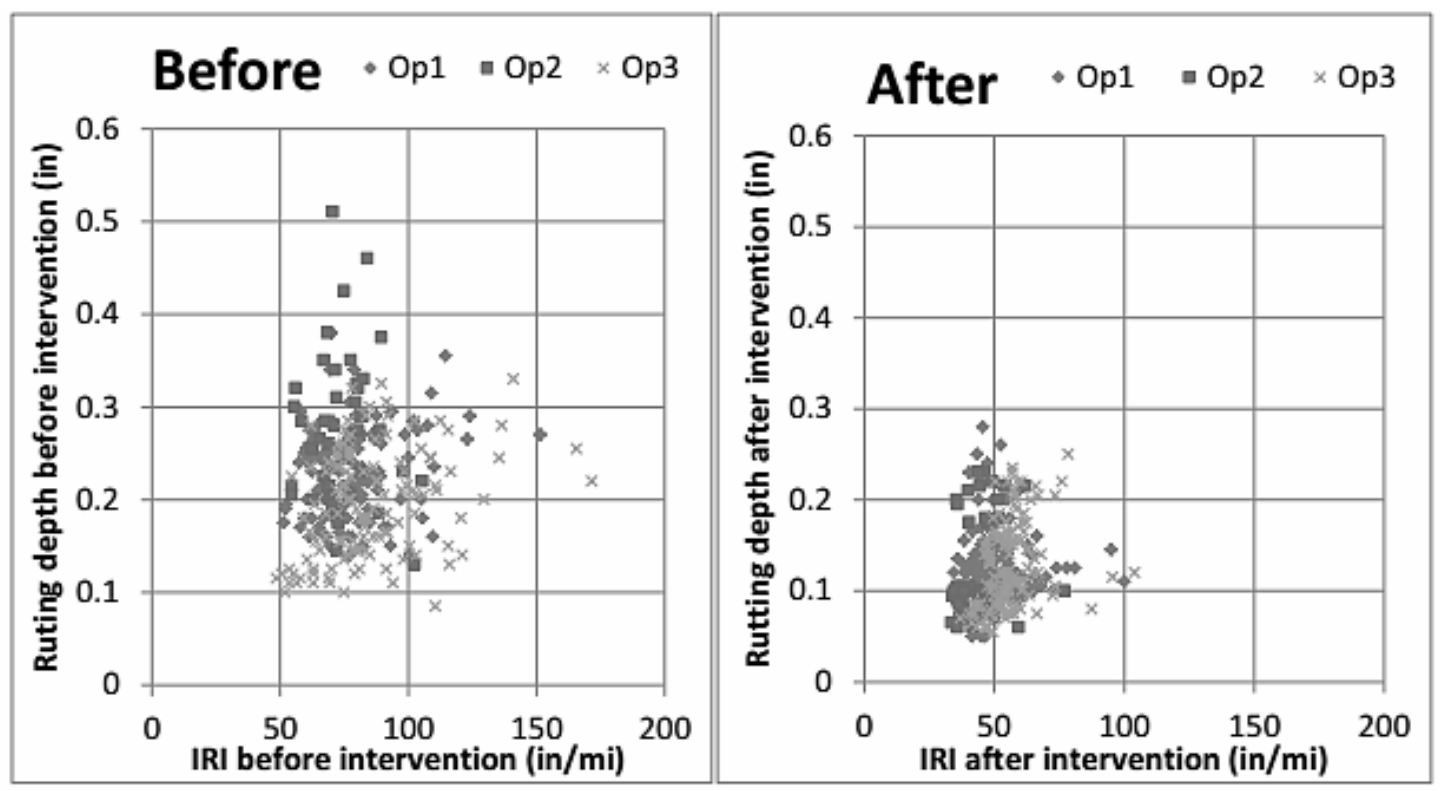

Figure 3. Pavement performance (IRI and rutting depth) before or after Option 1, Option 2, and Option $3(1 \mathrm{in}=25.4 \mathrm{~mm}, 1 \mathrm{in} / \mathrm{mi}=0.0158 \mathrm{~m} / \mathrm{km})$.

The statistics of indices before/after interventions and the improvements are presented in Table 1. The effects of Option 2 and Option 3 on IRI were similar, however the effect of Option 3 had larger standard deviation. Option 3 was performed on sections with higher IRI on average. The rutting depth after maintenance was similar for all the three interventions. It was probably because the interventions reset rutting and additional minor rutting occurred after maintenance and before the post-maintenance condition monitoring was made. Because such interventions were 
commonly performed on pavements at a late stage of the life, the development of rutting was slow.

Table 1. Statistics on performance indices before \& after interventions and improvement $(1 \mathrm{in}=25.4 \mathrm{~mm}, 1 \mathrm{in} / \mathrm{mi}=0.0158 \mathrm{~m} / \mathrm{km})$.

\begin{tabular}{|c|c|c|c|c|c|c|}
\hline Intervention & \multicolumn{2}{|c|}{ Option 1 } & \multicolumn{2}{c|}{ Option 2 } & \multicolumn{2}{c|}{ Option 3 } \\
\hline Number of points & \multicolumn{2}{|c|}{114} & \multicolumn{2}{c|}{45} & \multicolumn{2}{c|}{122} \\
\hline Statistics & $\begin{array}{c}\text { Mean } \\
(\mu)\end{array}$ & $\begin{array}{c}\text { Standard } \\
\text { deviation } \\
(\sigma)\end{array}$ & $\begin{array}{c}\text { Mean } \\
(\mu)\end{array}$ & $\begin{array}{c}\text { Standard } \\
\text { deviation } \\
(\sigma)\end{array}$ & $\begin{array}{c}\text { Mean } \\
(\mu)\end{array}$ & $\begin{array}{c}\text { Standard } \\
\text { deviation } \\
(\sigma)\end{array}$ \\
\hline $\begin{array}{c}\text { IRI before } \\
\text { intervention } \\
\text { (in/mi) }\end{array}$ & 78.64 & 16.60 & 74.72 & 11.53 & 86.28 & 24.30 \\
\hline $\begin{array}{c}\text { IRI after } \\
\text { intervention } \\
\text { (in/mi) }\end{array}$ & 51.53 & 10.71 & 43.57 & 8.65 & 56.05 & 9.84 \\
\hline $\begin{array}{c}\text { Improvement in } \\
\text { IRI (in/mi) }\end{array}$ & 27.11 & 13.66 & 30.86 & 9.00 & 30.23 & 21.54 \\
\hline $\begin{array}{c}\text { Rutting depth } \\
\text { before } \\
\text { intervention (in) }\end{array}$ & 0.23 & 0.049 & 0.27 & 0.079 & 0.20 & 0.059 \\
\hline $\begin{array}{c}\text { Rutting depth after } \\
\text { intervention (in) }\end{array}$ & 0.13 & 0.041 & 0.12 & 0.059 & 0.13 & 0.048 \\
\hline $\begin{array}{c}\text { Improvement in } \\
\text { rutting (in) }\end{array}$ & 0.10 & 0.046 & 0.15 & 0.068 & 0.07 & 0.046 \\
\hline
\end{tabular}

Commonly, maintenance effect models relate IRI after maintenance to the IRI before the intervention by linear regression. Such models are widely applied for modelling the immediate maintenance effects, including crack filling \& sealing, chip seal, slurry seal and overlays (Odoki and Kerali, 1999, ISOHDM, 1995, Djarf, 1995). The category of these interventions ranged from routine to corrective maintenance and thus this approach was used here to predict the immediate maintenance effects of the three options discussed. An example of such models from the Highway Development and Management Model (HDM-4) can be expressed as follows (ISOHDM, 1995): 
$\mathrm{IRI}_{\mathrm{a}}=\mathrm{a}_{0}+\mathrm{a}_{1} * \max \left(\mathrm{IRI}_{\mathrm{b}}-\mathrm{a}_{0}, 0\right) * \max \left(\mathrm{a}_{2}-\mathrm{HNEW}, 0\right) \quad$ (Equation 4)

Where,

$\mathrm{IRI}_{\mathrm{a}}=\mathrm{IRI}$ after an intervention

$\mathrm{IRI}_{\mathrm{b}}=\mathrm{IRI}$ before an intervention

HNEW $=$ the thickness of overlay

$\mathrm{a}_{0}, \mathrm{a}_{1}, \mathrm{a}_{2}=$ regression factors

To calculate the immediate maintenance effect, the $I_{R I}$ versus $I_{R I}$ type equation was restated in terms of an improvement versus $\mathrm{IRI}_{\mathrm{b}}$ type equation to emphasize the improvements. Furthermore, thickness, although an important factor for maintenance effects, was subsumed into the regression factors and not made an explicit variable.

The same linear model can be used to model the maintenance effects on rutting (Hall et al., 2002). The immediate maintenance effect models thus can be expressed as follows:

$\Delta \mathrm{IRI}_{\mathrm{n}}=\mathrm{a} * \mathrm{IRI}_{\mathrm{n} 0}+\mathrm{b}$

$\Delta$ Rut $_{\mathrm{n}}=\mathrm{c} * \mathrm{Rut}_{\mathrm{n} 0}+\mathrm{d}$

(Equation 6)

Where,

$\mathrm{a}, \mathrm{b}, \mathrm{c}, \mathrm{d}=$ regression factors

The value of the regression factors $a, b, c, d$ are probably related to the details of the intervention performed. For example, one would not expect, a priori, the same 
values for mill and fill with hot-mix asphalt as for cold-mix asphalt. Without more detailed information than is contained in the VDOT database, it is impossible to differentiate between such intervention factors. Therefore, for each intervention option, one set of regression factors are used irrespective of material type or minor change in thickness.

A fair match was observed between data and the equations for both IRI and rutting (see Figure 4). This indicated that the immediate maintenance effect was closely related to the pavement conditions before the maintenance. Furthermore, it seems that the material and thickness of the overlay had an impact on the maintenance effect on rutting (see Figure 4 right) because the improvement in rutting is generally larger for the 2 in overlays (50 mm, square points) than the 1.5 in ones ( $35 \mathrm{~mm}$, cross points), given a specific value of rutting depth before maintenance.

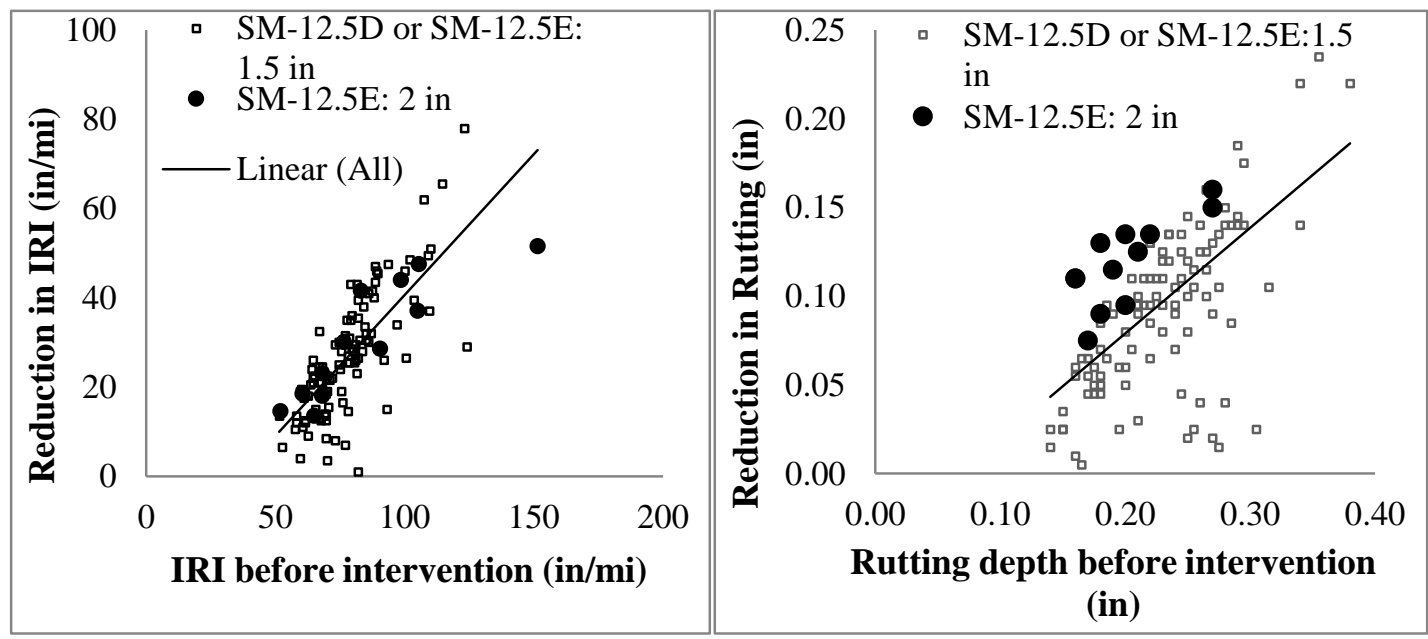

Figure 4. Maintenance effect on IRI and rutting of Option $1(1 \mathrm{in} / \mathrm{mi}=0.0158 \mathrm{~m} / \mathrm{km}, 1$ in $=25.4 \mathrm{~mm}$ ).

The calibrated factors for the three interventions were as given in Table 2:

Table 2. Results: regression factors $(1 \mathrm{in} / \mathrm{mi}=0.0158 \mathrm{~m} / \mathrm{km}, 1 \mathrm{in}=25.4 \mathrm{~mm})$.

\begin{tabular}{|l|l|l|l|l|}
\hline & IRI (in/mi) & Regression & Rutting depth (in) & Regression \\
\hline
\end{tabular}




\begin{tabular}{|l|c|c|c|c|c|c|}
\hline & $\mathrm{a}$ & $\mathrm{b}$ & $\mathrm{R}^{2}$ & $\mathrm{c}$ & $\mathrm{d}$ & $\mathrm{R}^{2}$ \\
\hline Option 1 & 0.6307 & -22.491 & 0.59 & 0.5956 & -0.0401 & 0.39 \\
\hline Option 2 & 0.5234 & -8.0962 & 0.45 & 0.5874 & -0.0117 & 0.46 \\
\hline Option 3 & 0.811 & -39.74 & 0.84 & 0.4752 & -0.0234 & 0.37 \\
\hline
\end{tabular}

Considering the distribution of IRI and rutting depth as being normal distributed, the range of IRI and rutting before interventions can be estimated from the mean \pm two standard deviations which will account for approximately $95 \%$ of available points. The validated maintenance effect models for the three maintenance options are presented in Figure 5. Generally, it can be seen that Option 3 (mill and fill) can correct rougher roads (average IRI before maintenance $=86.28 \mathrm{in} / \mathrm{mi}(1.36 \mathrm{~m} / \mathrm{km})$, see Table 1$)$ and Option 2 (two-layer overlay) can address deeper rutting (average rutting before maintenance $=0.27$ in $(7 \mathrm{~mm})$, see Table 1$)$. When IRI and rutting before intervention was rather low $(\mathrm{IRI}<100 \mathrm{in} / \mathrm{mi}(\approx 1.58 \mathrm{~m} / \mathrm{km}))$, the effects on both IRI and rutting of Option 2 are the greatest and Option 3 has the least effect (see Figure 5).

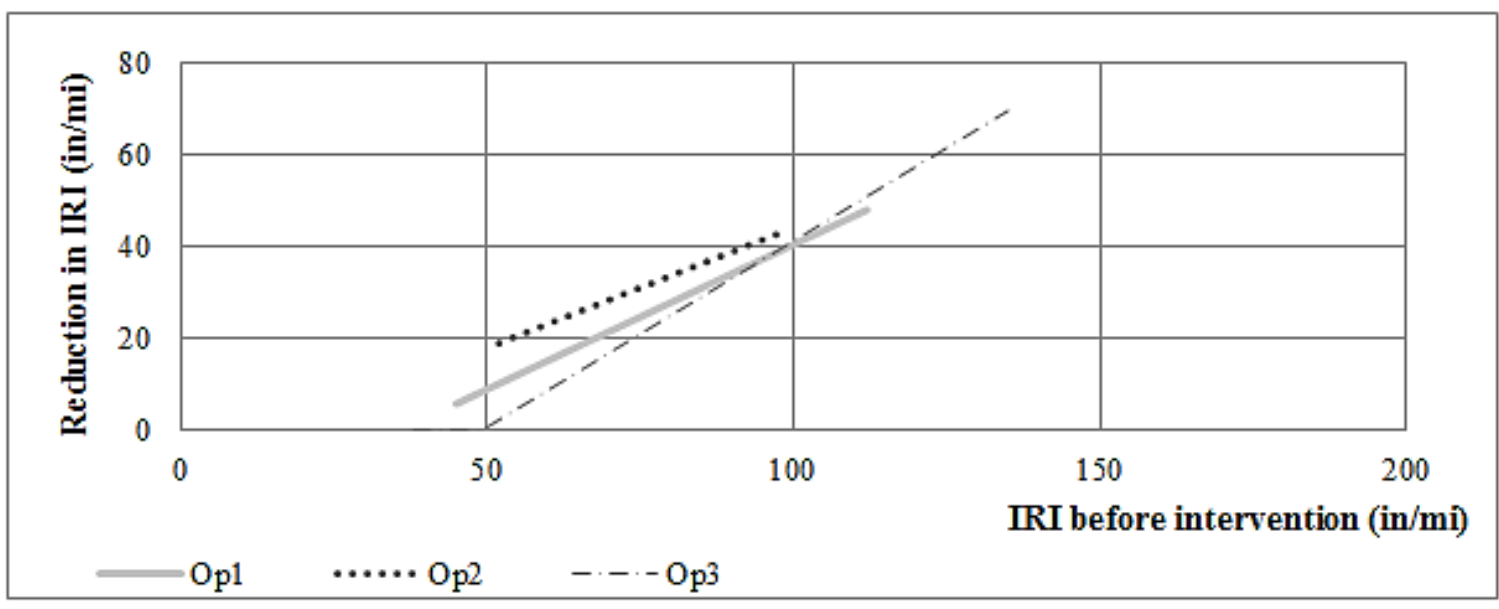




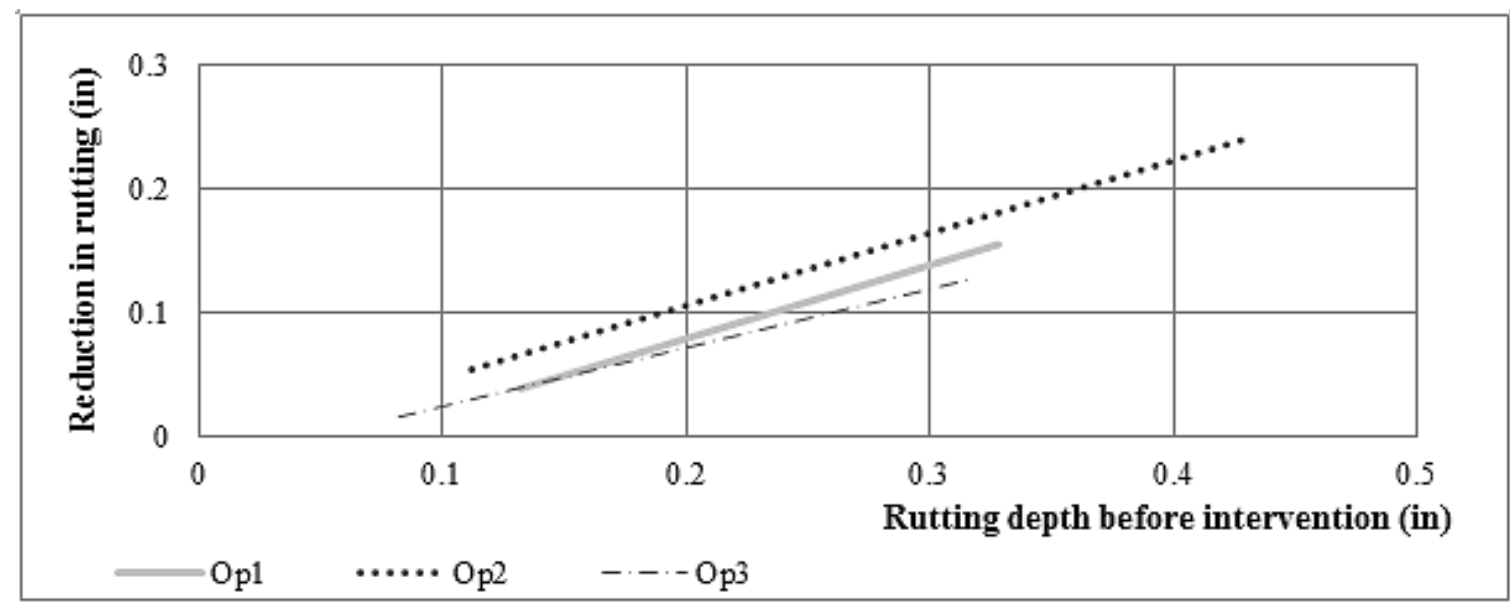

Figure 5. Maintenance effect models of the three interventions $(1 \mathrm{in} / \mathrm{mi}=0.0158 \mathrm{~m} / \mathrm{km}$, $1 \mathrm{in}=25.4 \mathrm{~mm})$.

\section{Conclusions}

This Technical Note introduced a method to validate some immediate maintenance effect models using PMS data. A flowchart was created to present the process of the data selection \& screening process. The following conclusions can be drawn based on the three interventions studied for data from several districts in Virginia (USA):

- The immediate maintenance effect including reduction in IRI and rutting can be associated with pavement conditions before maintenance.

- The immediate maintenance effect on rutting is influenced by layer thickness and material more than is the immediate improvement in IRI.

- Of the three maintenance options studied, Option 3 (mill \& fill) best addresses high levels of roughness (IRI > $100 \mathrm{in} / \mathrm{mi}(1.58 \mathrm{~m} / \mathrm{km})$ ). Option 2 (overlay with surface and base mixtures) best addresses deeper rutting (Rut depth $>0.3$ in (7.5 $\mathrm{mm})$ ). When pavement conditions before maintenance were fairly good (IRI < 
$100 \mathrm{in} / \mathrm{mi}(\approx 1.58 \mathrm{~m} / \mathrm{km}))$, the effectiveness of maintenance of the three options on both IRI and rutting ranks Option $2>$ Option $1>$ Option 3.

The following measures can be advised to road agencies:

- Performance measurements should be recorded so that it becomes possible to estimate the days/traffic between an intervention and the performance measurement. With several post-intervention performance measurements over a period of time, it would then be possible to back-figure the condition immediately after an intervention. In this way, a more precise assessment of the effect of the intervention will be achievable.

\section{References}

DJARF, L. 1995. Road Deterioration and Maintenance Effects Models in Cold Climates. Stockholm: Swedish Road Research Institute.

HALL, K. T., CORREA, C. E. \& SIMPSON, A. L. 2002. LTPP Data Analysis: Effectiveness of Maintenance and Rehabilitation Options. NCHRP Web Document 47 (Project 20-50[3/4]): Contractor's final report.

HICKS, R. G., SEEDS, B. S. \& PESHKIN, D. G. 2000. Select a Preventive Maintenance Treatment for Flexible Pavements. In: PRESERVATION, F. F. P. (ed.). Washington, D.C.

ISOHDM 1995. Modelling Road Deterioration and Maintenance Effects in HDM-4. International Study of Highway Development and Management Tools, RETA 5549-REG Highway Development and Management Research, Final Reports.

JOHANNS, M. \& CRAIG, J. 2002. Pavement Maintenance Manual. In: ROADS, N. D. O. (ed.).

MCDONALD, B. 2002. A Teaching Note on Cook's Distance - a Guideline. Res. Lett. Inf. Math. Sci 3, 127 - 128.

MTAG 2008. Maintenance Technical Advisory Guide. Volume 1: Flexible Pavement Preservation (Second Edition). State of California Department of Transportation.

ODOKI, J. B. \& KERALI, H. G. R. 1999. Volume Four: HDM-4 Technical Reference Manual. HDM-4 Manual (Version V1.0E). In: MANAGEMENT, H. D. (ed.).

QIAO, Y. 2015. Flexible pavements and climate change: impact of climate change on the performance, maintenance, and life-cycle costs of flexible pavements. $\mathrm{PhD}$ thesis, University of Nottingham. 
QIAO, Y., DAWSON, A., HUVSTIG, A. \& KORKIALA-TANTTU, L. 2014. Calculating rutting of some thin flexible pavements from repeated load triaxial test data. International Journal of Pavement Engineering, 16, 467-476.

QIAO, Y., DAWSON, A. R., PARRY, T. \& FLINTSCH, G. W. 2015. Evaluating the effects of climate change on road maintenance intervention strategies and Life-Cycle Costs. Transportation Research Part D: Transport and Environment, 41, 492-503.

QIAO, Y., FLINTSCH, G., DAWSON, A. \& PARRY, T. 2013. Examining Effects of Climatic Factors on Flexible Pavement Performance and Service Life. Transportation Research Record: Journal of the Transportation Research Board, 2349, 100-107.

SAYERS, M. W. \& KARAMIHAS, S. M. 1998. the Little Book of Profiling, University of Michigan. 